\title{
Prognostic Impact of Plasma Volume Estimated from Hemoglobin and Hematocrit in Heart Failure with Preserved Ejection Fraction
}

\author{
Masatake Kobayashi ${ }^{1 *}$, Nicolas Girerd ${ }^{1 *}$, Kevin Duarte ${ }^{1}$, Gregoire Preud'homme ${ }^{1}$, \\ Bertram Pitt ${ }^{2}$, Patrick Rossignol ${ }^{1}$ \\ *Equally contributed
}

1. Université de Lorraine, INSERM, Centre d'Investigations Cliniques 1433, CHRU de Nancy, Inserm 1116 and INI-CRCT (Cardiovascular and Renal Clinical Trialists) F-CRIN Network, Nancy, France.

2. Department of Medicine, University of Michigan School of Medicine, Ann Arbor, Michigan, USA.

\section{Corresponding Author:}

Pr. Patrick Rossignol

Centre d'Investigation Clinique Pierre Drouin -INSERM - CHRU de Nancy, Institut lorrain du cœur et des, vaisseaux Louis Mathieu, Nancy, France

Address : 4, rue du Morvan. 54500 Vandoeuvre-Les-Nancy

E-mail: p.rossignol@chru-nancy.fr

Short title: Estimated plasma volume status in HFpEF patients

Keywords: Plasma volume, hemoglobin, hematocrit, congestion, heart failure with preserved ejection fraction

Total number of tables and figures: tables 3 figures 2 


\section{Abstract \\ Background}

Plasma volume (PV) estimated from Duarte's formula (based on hemoglobin/hematocrit) has been associated with poor prognosis in patients with heart failure (HF). There are, however, limited data regarding the association of estimated PV status (ePVS) derived from hemoglobin/hematocrit with clinical profiles and study outcomes in patients with $\mathrm{HF}$ and preserved ejection fraction (HFpEF).

\section{Methods and results}

Patients from North and South America enrolled in the Treatment of Preserved Cardiac Function Heart Failure with an Aldosterone Antagonist trial (TOPCAT) with available hemoglobin/hematocrit data were studied. The association between ePVS (Duarte formula and Hakim formula) and the composite of cardiovascular mortality, HF hospitalization or aborted cardiac arrest was assessed. Among 1,747 patients (age 71.6 years; males 50.1\%), mean ePVS derived from Duarte formula was 4.9 $\pm 1.0 \mathrm{ml} / \mathrm{g}$. Higher Duarte-derived ePVS was associated with prior HF admission, diabetes, more severe congestion, poor renal function, higher natriuretic peptide level and E/e'. After adjustment for potential covariates including natriuretic peptide, higher Duarte-derived ePVS was associated with an increased rate of the primary outcome [highest vs. lowest ePVS quartile: adjusted-HR $(95 \% \mathrm{CI})=1.79$ (1.28-2.50), $\mathrm{p}<0.001]$. Duarte-derived ePVS improved prognostic performance on top of clinical and routine variables (including natriuretic peptides) $(\mathrm{NRI}=11, \mathrm{P}<0.001)$, whereas Hakim-derived ePVS did not $(\mathrm{P}=0.59)$. The prognostic value of Duarte-derived ePVS was not modified by renal function ( $\mathrm{p}$ interaction $>0.10$ for all outcomes).

\section{Conclusion}

ePVS from Duarte's formula was associated with congestion status and improved risk-stratification, regardless of renal function. Our findings suggest that Duarte-derived ePVS is a useful congestion variable in patients with HFpEF. 


\section{Introduction}

Patients with heart failure (HF) often present signs and symptoms of congestion, which is one of the main causes of hospitalization. Hospitalization for worsening HF has been associated with a higher risk of cardiovascular death ${ }^{1,2}$. There is a large body of literature regarding the clinical importance of assessing and monitoring congestion repeatedly before its progression to decompensation or during decongestion therapy ${ }^{1,3-6}$. However, there is little consensus among clinicians with regard to the strategy for the quantification and monitoring of congestion. A readily available and inexpensive monitoring tool to assess patients' congestion status may represent a valuable avenue of investigation.

Plasma volume (PV) is a marker of volume overload ${ }^{7,8}$, and patients with decompensated HF exhibit a $40 \%$ increase in PV compared with healthy controls ${ }^{9}$. PV may be estimated from the Duarte formula (based on hemoglobin and hematocrit) or from the Hakim formula (based on hematocrit and dry body weight), both of which have been reported to be associated with clinical outcomes in patients with acute HF and HF with reduced ejection fraction (HFrEF) ${ }^{10-16}$. However, despite published data on the different fluid distributions between HFrEF and preserved ejection fraction (HFpEF) ${ }^{17,18}$, whether estimated plasma volume status (ePVS) contributes to poor clinical outcome in patients with HFpEF has not been sufficiently investigated ${ }^{19,20}$. Recent data showed that the Duarte formula rather than Hakim formula was associated with left-sided hemodynamic marker of congestion ${ }^{21}$. It is however unclear which ePVS formula, between the Duarte formula and Hakim formula, has better risk stratification in this setting. Furthermore, previous studies have shown a significant association between ePVS and renal function ${ }^{12,13,16,20,22}$, although whether the prognostic value of ePVS may be influenced by renal function is yet to be studied in HFpEF.

The main objectives of the present study were to: 1) determine the association between clinical characteristics and other congestion variables using Duarte-derived ePVS; 2) study the association between Duarte-derived ePVS and study outcomes; 3) compare the discriminative prognostic values of Duarte-derived ePVS and Hakim-derived ePVS on top of the clinical model; 4) assess whether the prognostic value of Duarte-derived ePVS is modified by renal function, i.e. the presence of chronic kidney disease as defined by an estimated glomerular filtration rate (eGFR) below $60 \mathrm{ml} / \mathrm{min} / 1.73 \mathrm{~m}^{2}$. 


\section{Methods}

\section{Study Population}

The present study consists of a post-hoc analysis of data obtained in the Treatment of Preserved Cardiac Function Heart Failure with an Aldosterone Antagonist (TOPCAT) trial ${ }^{23}$. Inclusion criteria were age 50 years or older, $>1$ sign and at least one symptom of $\mathrm{HF}$, left ventricular ejection fraction $($ LVEF $) \geq 45 \%$, controlled systolic blood pressure and serum potassium $<5.0 \mathrm{mmol} / \mathrm{L}$. Additional criteria were either a history of HF hospitalization within the prior 12 months, or B-type natriuretic peptide $(\mathrm{BNP}) \geq 100 \mathrm{pg} / \mathrm{mL}$ or N-terminal pro-BNP (NT-proBNP) $\geq 360 \mathrm{pg} / \mathrm{mL}$ within 60 days prior to randomization. Due to previously published regional differences in patient characteristics, outcomes, and response to spironolactone between patients enrolled in Russia/Georgia and the Americas ${ }^{24}$, the current study was analyzed in patients who had available hemoglobin/hematocrit data in the Americas (United States, Canada, Brazil and Argentina). Each site approved the protocols and all patients signed informed consent prior to randomization. This study complies with the Declaration of Helsinki and the local Institutional Review Board has approved this research.

\section{Estimated Plasma Volume Status}

ePVS was calculated from the Strauss-derived Duarte formula using hematocrit and hemoglobin ${ }^{10,25}$ as follows:

ePVS $(\mathrm{mL} / \mathrm{g})=100 \times(1$-hematocrit $) /$ hemoglobin in $\mathrm{g} / \mathrm{dL}$

The Hakim formula was also used for calculating PV estimation derived from hematocrit and dry body weight using the following equations ${ }^{26}$ :

Actual plasma volume $=(1$-hematocrit $) \times(\mathrm{a}+\mathrm{b} \times$ body weight in $\mathrm{kg})$

Ideal plasma volume $=\mathrm{c} \times$ body weight in $\mathrm{kg}$

(males: $a=1530, b=41.0, c=39$; females; $a=864, b=47.9, c=40$ ),

ePVS=[(actual plasma volume - ideal plasma volume $) /$ ideal plasma volume $] \times 100$. 


\section{Study Outcomes}

The primary outcome of TOPCAT was the composite of cardiovascular mortality, HF hospitalization or aborted cardiac arrest. The current analysis also included all-cause mortality, cardiovascular mortality and HF hospitalization as previously published ${ }^{23}$. Cardiovascular mortality was defined by any death from myocardial infarction, pump failure, sudden death, stroke, pulmonary embolism or others. Patients hospitalized for worsening HF needed to meet at least one symptom, 2 signs of congestion and requiring decongestion treatment.

\section{Statistical Analysis}

Categorical variables are expressed as frequencies (percentages) and continuous variables as means \pm standard deviation or median (25th and 75th percentiles) according to the distribution of the variables. Comparisons of demographic, clinical, biological and echocardiographic parameters among ePVS quartiles were analyzed using $\chi^{2}$ tests for categorical variables and ANOVA or Kruskal-Wallis test for continuous variables. Patients were also divided into four groups according to the categories of ePVS and eGFR calculated by the Modification of Diet in Renal Disease formula ${ }^{27}$.

Linear regression analyses were performed to assess the associations of clinical, biological and echocardiographic variables with ePVS. Variables were entered into the multivariable model with backward selection. Covariates considered to be of potential predictive impact comprised 34 baseline patient characteristics (Supplementary table 1). These variables had a small proportion of missing values $(<10 \%)$, and no multiple imputation was performed. Internal validation of the model was performed by bootstrapping (x200).

Time-to-event comparisons were analyzed using log rank test and Cox proportional hazards models. Survival probabilities were estimated using the Kaplan-Meier method and plotted as survival curves with ePVS quartiles and ePVS/eGFR categories, respectively. Cox proportional hazards models were then used to obtain unadjusted and covariate adjusted hazard ratios (HRs). Time-to-event analysis for HF hospitalization was conducted using a competing risk model as described by Fine and Gray ${ }^{28}$, with HF hospitalization as the outcome and all-cause mortality as the competing risk. The covariates used for adjustment included age, sex, BMI, previous myocardial infarction, NYHA III or 
IV, LVEF, potassium and eGFR at baseline. An additional adjustment consisting of the aforementioned covariates plus log-transformed standardized (z-score) natriuretic peptide (i.e., BNP or NT-proBNP) was also performed. Interactions between ePVS and eGFR on clinical outcomes were assessed using both continuous and categorical variables.

Continuous net reclassification improvement (NRI) and integrated diagnostic improvement (IDI) were calculated to estimate an improvement in risk prediction of the primary outcome by the addition of ePVS on top of the aforementioned variables ${ }^{29}$.

All analyses were performed using R (R Development Core Team, Vienna, Austria). A twosided p-value $<0.05$ was considered statistically significant.

\section{Results}

\section{Baseline Characteristics}

Among the 1,747 patients included in this study, half of the patients $(\mathrm{N}=875)$ were male, mean age was $71.6 \pm 9.7$ years, mean BMI was $33.8 \pm 8.1 \mathrm{~kg} / \mathrm{m}^{2}$ and over half had a prior admission for HF $(58.8 \%)$ (Table 1).

Mean ePVS was $4.9 \pm 1.0 \mathrm{ml} / \mathrm{g}$. Patients with higher ePVS were more likely to have atrial fibrillation, prior HF admission, more severe congestion, poorer renal function, higher natriuretic peptide level, E/e' and a more impaired quality of life (Table 1).

\section{Clinical Determinants of Estimated Plasma Volume Status}

In the linear regression models, poorer renal function, prior HF admission, congestion signs/symptoms (i.e., NYHA, orthopnea, jugular venous distention and leg edema), female sex, diabetes and use of beta-blocker remained significantly associated with higher ePVS levels (Table 2). Similar results were obtained in considering the highest ePVS quartiles as outcome (Supplementary table 2). 


\section{Survival Analysis}

During a median follow up of 2.5 years, $29.6 \%, 22.0 \%$ and $22.7 \%$ of patients met the primary outcome, all-cause mortality and HF hospitalization, respectively. The primary outcome occurred more frequently in patients with higher ePVS (Figure 1). Compared with the lowest quartile, the highest ePVS quartile $(>5.5 \mathrm{ml} / \mathrm{g}$ ) was associated with a doubling of the rates of the primary outcome [adjusted-HR $(95 \% \mathrm{CI})=2.00(1.55-2.59), \mathrm{p}<0.001]$ (Table 3). After further adjustment for covariates including natriuretic peptide, the highest ePVS quartiles remained significantly associated with the primary outcome [adjusted-HR $(95 \% \mathrm{CI})=1.79(1.28-2.50), \mathrm{p}<0.001]$. Similarly, the highest ePVS level was associated with increased HF hospitalization rates (Supplementary table 3).

In univariable model, when compared with patients with low ePVS $(<5.5 \mathrm{ml} / \mathrm{g})$ and high eGFR $\left(>60 \mathrm{ml} / \mathrm{min} / 1.73 \mathrm{~m}^{2}\right)$, patients with high ePVS $(>5.5 \mathrm{ml} / \mathrm{g})$ with either lower eGFR $\left(<60 \mathrm{ml} / \mathrm{min} / 1.73 \mathrm{~m}^{2}\right)$ or higher eGFR $\left(>60 \mathrm{ml} / \mathrm{min} / 1.73 \mathrm{~m}^{2}\right)$ had a significantly higher risk of the primary outcome [respectively HR $(95 \% \mathrm{CI})=2.65(2.08-3.37), \mathrm{p}<0.001 ; \mathrm{HR}(95 \% \mathrm{CI})=1.90(1.41-2.55), \mathrm{p}<0.001]$. After adjusting for potential confounders including natriuretic peptide, patients with high ePVS expressed an increased risk of similar magnitude for the primary outcome in patients with lower and higher eGFR

(Table 3). Concordantly, patients with higher ePVS were associated with a higher risk of other clinical outcomes irrespective of eGFR level (Supplementary table 3).

There was no significant interaction between ePVS and eGFR on study outcomes (all-P interaction>0.1). In addition, no interaction was found between ePVS and spironolactone (all-P interaction $>0.1)$.

\section{Estimated Plasma Volume Status on Top of the Clinical Models}

In the current analysis, patients in the highest quartile of Duarte-derived ePVS ( $>5.5 \mathrm{ml} / \mathrm{g}$ ) had a worse prognosis. The addition of Duarte-derived ePVS (>5.5ml/g) significantly improved reclassification $[\mathrm{NRI}(95 \% \mathrm{CI})=10.1(3.2-16.5), \mathrm{p}=0.004$ and IDI $(95 \% \mathrm{CI})=1.3(0.4-2.7), \mathrm{p}<0.001]$ on the aforementioned potential covariates, whereas the addition of higher Hakim-derived ePVS (>0\%) did not (Figure 2 \& Supplementary table 4). Furthermore, Duarte-derived ePVS still significantly 
improved reclassification [NRI $(95 \% \mathrm{CI})=10.3(2.9-18.5), \mathrm{p}<0.001$ and IDI $(95 \% \mathrm{CI})=0.80(0.01-2.10)$, $\mathrm{p}=0.04]$ on top of a model containing the Hakim-derived ePVS and baseline clinical variables.

\section{Discussion}

The present study investigated the clinical and prognostic impact of Duarte-derived ePVS in patients with HFpEF. Our main findings were; 1) higher Duarte-derived ePVS was associated with a more severe congestion status; 2) higher Duarte-derived ePVS was independently associated with a higher-risk of study outcomes; 3) the Duarte-derived ePVS prognosis value persisted irrespective of renal function; 4) Duarte-derived ePVS significantly improved risk-stratification on top of clinical and routine biological variables (including natriuretic peptides), whereas the Hakim-derived ePVS did not. Our findings suggest that PV estimated from the Duarte formula may provide better patient risk stratification than the Hakim formula in patients with HFpEF.

\section{Duarte-Derived Estimated Plasma Volume Status as a Better Prognostic Marker}

In the present analysis, median Duarte-derived ePVS was $4.9 \pm 1.0 \mathrm{ml} / \mathrm{g}$, which is in line with previous reports ${ }^{10,12,19}$. Our results furthermore showed that Duarte-derived ePVS was associated with the primary outcome. In a previous post-hoc analysis of TOPCAT, ePVS values were calculated based on the Hakim formula in 3,414 patients with CHF and LVEF $>45 \%{ }^{20}$. Within 5 years (during which $19.2 \%$ of patients met the primary outcome), higher ePVS ( $>0 \%)$ was significantly associated with a higher incidence of the primary outcome. However, given the well-known regional differences in the TOPCAT trial ${ }^{24}$, analyzing the individuals enrolled in the Americas has proven to be more informative. In this latter subset, and contrary to the results herein using the Duarte-derived formula, higher ePVS was not significantly associated with study outcomes in multivariable Cox models adjusted for natriuretic peptide (e.g. HR=1.06 (0.98 - 1.16) p=0.17 for the primary endpoint). In a previous report assessing the association between Duarte-derived ePVS and the composite of HF hospitalization or all-cause mortality in 449 patients with $\mathrm{HFpEF}^{19}$, after a median follow-up of 10.7 years, the best-cut off point, ePVS $>5.5 \mathrm{ml} / \mathrm{g}$, was found to associated with poor outcomes $(21.6 \%$ of patients died and $24.7 \%$ had HF hospitalization) ${ }^{19}$. However, the analyses were not adjusted for natriuretic peptide, which could result in residual confounding. 
To the best of our knowledge, the present study is the first to assess the prognostic/riskstratification value of Duarte-derived ePVS and Hakim-derived ePVS on top of clinical and routine biological covariates (including natriuretic peptides). By demonstrating a significant reclassification improvement of ePVS derived from Duarte formula but not Hakim formula, our findings suggest a better prognostic utility of Duarte-derived ePVS in patients with HFpEF. The main difference in the aforementioned ePVS formulas is the use of dry body weight in the Hakim formula. Given the complex interplay between congestion and cardiac cachexia in patients with $\mathrm{HF}^{30,31}$, dry body weight may represent a difficult variable to assess and could introduce major bias in the formula.

Previous reports have shown different fluid profiles between patients with $\mathrm{HFpEF}$ and HFrEF 32, 33. Miller et al. compared body fluid profiles measured using the ${ }^{131}$ I-labeled albumin method between patients with HFpEF and HFrEF ${ }^{17}$. Their results showed that patients with HFpEF had a higher interstitial fluid volume with higher body weight compared with those with HFrEF, suggesting greater extravascular volume distribution in patients with HFpEF. These results may explain why dry body weight is less associated with PV in patients with HFpEF, leading to the limited prognostic value of the Hakim-derived ePVS in this setting.

\section{Duarte-Derived ePVS as a Congestion Marker and its Interplay with Renal Function}

In the current study, patients with higher Duarte-derived ePVS were associated with a more severe congestion status as assessed by clinical variables (NYHA III or IV, orthopnea, jugular venous distention and leg edema), NT-proBNP and E/e'. These results support the premise that ePVS derived from hemoglobin/hematocrit is an integrative congestion marker in HFpEF. Previous studies assessing the change in hemoglobin or hematocrit showed an association with clinical assessments of congestion ${ }^{34-36}$. Recent reports also showed a significant association of hemoglobin with biological, ultrasound or radiographic measures of congestion in ambulatory HF patients with fewer signs/symptoms of congestion ${ }^{37,38}$. Hemoglobin itself is thus likely to be the preferred marker with high sensitivity for the assessment or monitoring of congestion in conjunction with lung ultrasound or natriuretic peptide

${ }^{1,39}$. Furthermore, a recent meta-analysis assessed the association between clinical profiles and 
measured blood volume components in 368 patients with HF. Their results showed that hemoglobin was significantly associated with measured PV, but not with blood volume ${ }^{40}$. These findings further strengthen that Duarte-derived ePVS could potentially become an easy-to-use and promising assessment tool for evaluating congestion/plasma volume in patients with HF.

Renal functional deterioration enhances neurohormonal activation, leading to increased PV values ${ }^{41}$. Renal venous congestion due to increased PV has been implicated in the pathogenesis of renal impairment ${ }^{42}$, whereas decreased PV, similar to hemoconcentration, is also associated with worsening renal function ${ }^{34-36}$. Despite this reported intimate relationship between PV and renal function, we did not find any statistical interaction between ePVS and eGFR with regard to study outcomes. Our observations thus suggest that Duarte-derived ePVS may help clinicians in better identifying patients at higher risk of cardiovascular events regardless of renal function.

\section{Clinical perspective}

Hemodynamic congestion begins gradually and ultimately results in symptomatic congestion and/or urgent hospitalization. Close biological monitoring of congestion may therefore provide better stratification of patient risk. Accordingly, plasma volume, estimated from hemoglobin/hematocrit using Duarte's formula, may represent an easy-to-use marker in patients with HFpEF in clinical routine.

In the present study, the highest quartile of PV estimated from Duarte's formula ( $\geq 5.5 \mathrm{ml} / \mathrm{g}$ ) appeared to drive a higher risk of study outcomes regardless of renal function. This threshold for the prognostic value of ePVS $(\geq 5.5 \mathrm{ml} / \mathrm{g})$ is in keeping with recent data regarding ePVS in patients with

acute or chronic $\mathrm{HF}^{12,13,19}$. Further studies are needed to determine whether this threshold may help optimize decongestion therapy and the monitoring of ambulatory patients.

\section{Limitations}

The present study has several limitations. This is a post-hoc analysis of the TOPCAT trial and thus, given its inherent limitations, we are unable to infer causality nor exclude residual confounders. First, no direct measurement of PV was performed by conventional radioisotope-labeled albumin or 
red blood cell assays, although these techniques are relatively impractical in routine clinical practice given their high cost and technical requirements. Second, we did not have access to serial hemoglobin/hematocrit measurements. Changes in ePVS, especially by the effect of mineralocorticoid receptor antagonist, may also provide good patient risk stratification ${ }^{43}$. Third, we cannot exclude analytical or laboratory variability introduced by natriuretic peptide measured at the clinical site laboratories.

\section{Conclusion}

Duarte-derived ePVS appears as an integrative congestion variable capable of improving patient risk-stratification, whereas the Hakim-derived ePVS did not. Duarte-derived ePVS provided prognostic information irrespective of renal function. Our findings suggest that ePVS derived from hemoglobin/hematocrit alone could be clinically useful for quantifying congestion status in patients with HFpEF.

\section{Acknowledgements}

The TOPCAT trial was funded and sponsored by the NHLBI.

The Nancy team is supported by the RHU Fight-HF, a public grant overseen by the French National Research Agency (ANR) as part of the second "Investissements d'Avenir" program (reference: ANR15-RHUS-0004), by the French PIA project "Lorraine Université d'Excellence" (reference: ANR-15IDEX-04-LUE), the ANR FOCUS-MR (reference: ANR-15-CE14-0032-01), ERA-CVD EXPERT (reference: ANR-16-ECVD-0002-02), Contrat de Plan Etat Lorraine IT2MP and FEDER Lorraine.

\section{Disclosures}

P.R. reports grants and personal fees from AstraZeneca, grants and personal fees from Bayer, grants and personal fees from CVRx, personal fees from Fresenius, grants and personal fees from Novartis, personal fees from Grunenthal, personal fees from Servier, personal fees from Stealth Peptides, personal fees from Vifor Fresenius Medical Care Renal Pharma, personal fees from Idorsia, personal 
fees from NovoNordisk, personal fees from Ablative Solutions, personal fees from G3P, personal fees from Corvidia, personal fees from Relypsa, outside the submitted work; and Cofounder: CardioRenal, a company developing a telemonitoring loop in heart failure (including potassium measurements).

B.P. reports personal fees (consulting) from Bayer, KBP Pharmaceuticals, AstraZeneca,

Relypsa/Vifor, Sanofi, sc Pharmaceuticals, Sarfez pharmaceuticals, Stealth Peptides, Cereno

Scientific, SQinnovations, G3 pharmaceuticals, Ardelyx and Tricida; stock options from KBP

Pharmaceuticals, sc Pharmaceuticals, Sarfez pharmaceuticals, Relypsa, Cereno scientific,

SQinnovations, G3 pharmaceuticals, Ardelyx and Tricida; patent for site specific delivery of eplerenone to the myocardium US patent Number 9931412. N.G. reports honoraria from Novartis and Boehringer. All other authors have no conflicts to disclose.

\section{References}

1. Girerd N, Seronde MF, Coiro S, Chouihed T, Bilbault P, Braun F, Kenizou D, Maillier B, Nazeyrollas P, Roul G, Fillieux L, Abraham WT, Januzzi J, Jr., Sebbag L, Zannad F, Mebazaa A and Rossignol P. Integrative Assessment of Congestion in Heart Failure Throughout the Patient Journey. JACC Heart Fail. 2018;6:273-285. 2. Pokorney SD, Al-Khatib SM, Sun JL, Schulte P, O'Connor CM, Teerlink JR, Armstrong PW, Ezekowitz JA, Starling RC, Voors AA, Velazquez EJ, Hernandez AF and Mentz RJ. Sudden cardiac death after acute heart failure hospital admission: insights from ASCEND-HF. Eur J Heart Fail. 2018;20:525-532.

3. Gheorghiade M, Follath F, Ponikowski P, Barsuk JH, Blair JE, Cleland JG, Dickstein K, Drazner MH, Fonarow GC, Jaarsma T, Jondeau G, Sendon JL, Mebazaa A, Metra M, Nieminen M, Pang PS, Seferovic P, Stevenson LW, van Veldhuisen DJ, Zannad F, Anker SD, Rhodes A, McMurray JJ, Filippatos G, European Society of C and European Society of Intensive Care M. Assessing and grading congestion in acute heart failure: a scientific statement from the acute heart failure committee of the heart failure association of the European Society of Cardiology and endorsed by the European Society of Intensive Care Medicine. Eur J Heart Fail. 2010;12:423-33.

4. Abraham WT, Adamson PB, Bourge RC, Aaron MF, Costanzo MR, Stevenson LW, Strickland W, Neelagaru S, Raval N, Krueger S, Weiner S, Shavelle D, Jeffries B and Yadav JS. Wireless pulmonary artery haemodynamic monitoring in chronic heart failure: a randomised controlled trial. Lancet. 2011;377:658-66. 5. Ambrosy AP, Pang PS, Khan S, Konstam MA, Fonarow GC, Traver B, Maggioni AP, Cook T, Swedberg K, Burnett JC, Jr., Grinfeld L, Udelson JE, Zannad F and Gheorghiade M. Clinical course and predictive value of congestion during hospitalization in patients admitted for worsening signs and symptoms of heart failure with reduced ejection fraction: findings from the EVEREST trial. Eur Heart J. 2013;34:835-43. 
6. Coiro S, Girerd N, Rossignol P, Ferreira JP, Maggioni A, Pitt B, Tritto I, Ambrosio G, Dickstein K and Zannad F. Association of beta-blocker treatment with mortality following myocardial infarction in patients with chronic obstructive pulmonary disease and heart failure or left ventricular dysfunction: a propensity matchedcohort analysis from the High-Risk Myocardial Infarction Database Initiative. Eur J Heart Fail. 2016.

7. Francis GS, Benedict C, Johnstone DE, Kirlin PC, Nicklas J, Liang CS, Kubo SH, Rudin-Toretsky E and Yusuf S. Comparison of neuroendocrine activation in patients with left ventricular dysfunction with and without congestive heart failure. A substudy of the Studies of Left Ventricular Dysfunction (SOLVD). Circulation. 1990;82:1724-9.

8. Miller WL. Fluid Volume Overload and Congestion in Heart Failure: Time to Reconsider Pathophysiology and How Volume Is Assessed. Circ Heart Fail. 2016;9:e002922.

9. Kaplan E, Puestow RC, Baker LA and Kruger S. Blood volume in congestive heart failure as determined with iodinated human serum albumin. Am Heart J. 1954;47:824-38.

10. Duarte K, Monnez JM, Albuisson E, Pitt B, Zannad F and Rossignol P. Prognostic Value of Estimated Plasma Volume in Heart Failure. JACC Heart Fail. 2015;3:886-93.

11. Ling HZ, Flint J, Damgaard M, Bonfils PK, Cheng AS, Aggarwal S, Velmurugan S, Mendonca M, Rashid M, Kang S, Papalia F, Weissert S, Coats CJ, Thomas M, Kuskowski M, Cohn JN, Woldman S, Anand IS and Okonko DO. Calculated plasma volume status and prognosis in chronic heart failure. Eur J Heart Fail. 2015;17:35-43.

12. Kobayashi M, Rossignol P, Ferreira JP, Aragao I, Paku Y, Iwasaki Y, Watanabe M, Fudim M, Duarte K, Zannad F and Girerd N. Prognostic value of estimated plasma volume in acute heart failure in three cohort studies. Clin Res Cardiol. 2018.

13. Chouihed T, Rossignol P, Bassand A, Duarte K, Kobayashi M, Jaeger D, Sadoune S, Buessler A, Nace L, Giacomin G, Hutter T, Barbe F, Salignac S, Jay N, Zannad F and Girerd N. Diagnostic and prognostic value of plasma volume status at emergency department admission in dyspneic patients: results from the PARADISE cohort. Clin Res Cardiol. 2018.

14. Yoshihisa A, Abe S, Sato Y, Watanabe S, Yokokawa T, Miura S, Misaka T, Sato T, Suzuki S, Oikawa M, Kobayashi A, Yamaki T, Kunii H, Saitoh SI and Takeishi Y. Plasma volume status predicts prognosis in patients with acute heart failure syndromes. Eur Heart J Acute Cardiovasc Care. 2017:2048872617690889. 15. Balderston JR, Shah KB, Paciulli SC and Gertz ZM. Usefulness of Estimated Plasma Volume at Postdischarge Follow-Up to Predict Recurrent Events in Patients With Heart Failure. Am J Cardiol. 2018;122:1191-1194.

16. Kobayashi M, Bercker M, Huttin O, Pierre S, Sadoul N, Bozec E, Chouihed T, Ferreira JP, Zannad F, Rossignol P and Girerd N. Chest X-ray quantification of admission lung congestion as a prognostic factor in patients admitted for worsening heart failure from the ICALOR cohort study. Int J Cardiol. 2019.

17. Miller WL and Mullan BP. Volume Overload Profiles in Patients With Preserved and Reduced Ejection Fraction Chronic Heart Failure: Are There Differences? A Pilot Study. JACC Heart Fail. 2016;4:453-9.

18. Takei M, Kohsaka S, Shiraishi Y, Goda A, Izumi Y, Yagawa M, Mizuno A, Sawano M, Inohara T, Kohno T, Fukuda K, Yoshikawa T and West Tokyo Heart Failure Registry I. Effect of estimated plasma volume reduction on renal function for acute heart failure differs between patients with preserved and reduced ejection fraction. Circulation Heart failure. 2015;8:527-32. 
19. Huang CY, Lin TT, Wu YF, Chiang FT and Wu CK. Long-term Prognostic Value of Estimated Plasma Volume in Heart Failure with Preserved Ejection Fraction. Sci Rep. 2019;9:14369.

20. Grodin JL, Philips S, Mullens W, Nijst P, Martens P, Fang JC, Drazner MH, Tang WHW and Pandey

A. Prognostic implications of plasma volume status estimates in heart failure with preserved ejection fraction: insights from TOPCAT. Eur J Heart Fail. 2019.

21. Kobayashi M, Huttin O, Donal E, Duarte K, Hubert A, Le Breton H, Galli E, Fournet M, Mabo P, Schnell F, Leclercq C, Rossignol P and Girerd N. Association of estimated plasma volume status with hemodynamic and echocardiographic parameters. Clin Res Cardiol. 2020.

22. Okonko DO, Jouhra F, Abu-Own H, Filippatos G, Colet JC, Suki C, Mori C, Ponikowski P and Anker SD. Effect of ferric carboxymaltose on calculated plasma volume status and clinical congestion: a FAIR-HF substudy. ESC Heart Fail. 2019;6:621-628.

23. Pitt B, Pfeffer MA, Assmann SF, Boineau R, Anand IS, Claggett B, Clausell N, Desai AS, Diaz R, Fleg JL, Gordeev I, Harty B, Heitner JF, Kenwood CT, Lewis EF, O'Meara E, Probstfield JL, Shaburishvili T, Shah SJ, Solomon SD, Sweitzer NK, Yang S and McKinlay SM. Spironolactone for heart failure with preserved ejection fraction. $N$ Engl J Med. 2014;370:1383-92.

24. Pfeffer MA, Claggett B, Assmann SF, Boineau R, Anand IS, Clausell N, Desai AS, Diaz R, Fleg JL, Gordeev I, Heitner JF, Lewis EF, O'Meara E, Rouleau JL, Probstfield JL, Shaburishvili T, Shah SJ, Solomon SD, Sweitzer NK, McKinlay SM and Pitt B. Regional variation in patients and outcomes in the Treatment of Preserved Cardiac Function Heart Failure With an Aldosterone Antagonist (TOPCAT) trial. Circulation. 2015;131:34-42.

25. Strauss MB, Davis RK, Rosenbaum JD and Rossmeisl EC. Water diuresis produced during recumbency by the intravenous infusion of isotonic saline solution. J Clin Invest. 1951;30:862-8.

26. RM. H. Plasmapheresis. In: I. D. JT, B. PG and I. TS, eds. Handbook of dialysis, 3rd ed Philadelphia: Lippincott. Williams and Wilkins; 2001: 236.

27. Levey AS, Bosch JP, Lewis JB, Greene T, Rogers N and Roth D. A more accurate method to estimate glomerular filtration rate from serum creatinine: a new prediction equation. Modification of Diet in Renal Disease Study Group. Ann Intern Med. 1999;130:461-70.

28. Fine JP and Gray RJ. A proportional hazards model for the subdistribution of a competing risk. $J \mathrm{Am}$ Stat Assoc. 1999;94:496-509.

29. Uno H, Tian L, Cai T, Kohane IS and Wei LJ. A unified inference procedure for a class of measures to assess improvement in risk prediction systems with survival data. Stat Med. 2013;32:2430-42.

30. Ambrosy AP, Cerbin LP, Armstrong PW, Butler J, Coles A, DeVore AD, Dunlap ME, Ezekowitz JA, Felker GM, Fudim M, Greene SJ, Hernandez AF, O'Connor CM, Schulte P, Starling RC, Teerlink JR, Voors AA and Mentz RJ. Body Weight Change During and After Hospitalization for Acute Heart Failure: Patient Characteristics, Markers of Congestion, and Outcomes: Findings From the ASCEND-HF Trial. JACC Heart Fail. 2017;5:1-13.

31. Anker SD, Negassa A, Coats AJS, Afzal R, Poole-Wilson PA, Cohn JN and Yusuf S. Prognostic importance of weight loss in chronic heart failure and the effect of treatment with angiotensin-convertingenzyme inhibitors: an observational study. The Lancet. 2003;361:1077-1083. 
32. Abramov D, Cohen RS, Katz SD, Mancini D and Maurer MS. Comparison of blood volume characteristics in anemic patients with low versus preserved left ventricular ejection fractions. Am J Cardiol. 2008;102:1069-72.

33. Schwartzenberg S, Redfield MM, From AM, Sorajja P, Nishimura RA and Borlaug BA. Effects of vasodilation in heart failure with preserved or reduced ejection fraction implications of distinct pathophysiologies on response to therapy. J Am Coll Cardiol. 2012;59:442-51.

34. Testani JM, Chen J, McCauley BD, Kimmel SE and Shannon RP. Potential effects of aggressive decongestion during the treatment of decompensated heart failure on renal function and survival. Circulation. 2010;122:265-72.

35. Greene SJ, Gheorghiade M, Vaduganathan M, Ambrosy AP, Mentz RJ, Subacius H, Maggioni AP, Nodari S, Konstam MA, Butler J, Filippatos G and investigators ET. Haemoconcentration, renal function, and post-discharge outcomes among patients hospitalized for heart failure with reduced ejection fraction: insights from the EVEREST trial. Eur J Heart Fail. 2013;15:1401-11.

36. van der Meer P, Postmus D, Ponikowski P, Cleland JG, O'Connor CM, Cotter G, Metra M, Davison BA, Givertz MM, Mansoor GA, Teerlink JR, Massie BM, Hillege HL and Voors AA. The predictive value of short-term changes in hemoglobin concentration in patients presenting with acute decompensated heart failure. $J$ Am Coll Cardiol. 2013;61:1973-81.

37. Pellicori P, Shah P, Cuthbert J, Urbinati A, Zhang J, Kallvikbacka-Bennett A, Clark AL and Cleland JGF. Prevalence, pattern and clinical relevance of ultrasound indices of congestion in outpatients with heart failure. Eur J Heart Fail. 2019;21:904-916.

38. Melenovsky V, Andersen MJ, Andress K, Reddy YN and Borlaug BA. Lung congestion in chronic heart failure: haemodynamic, clinical, and prognostic implications. Eur J Heart Fail. 2015;17:1161-71.

39. Daniels LB and Maisel AS. Natriuretic peptides. J Am Coll Cardiol. 2007;50:2357-68.

40. Montero D, Lundby C, Ruschitzka F and Flammer AJ. True Anemia-Red Blood Cell Volume Deficit-in Heart Failure: A Systematic Review. Circ Heart Fail. 2017;10.

41. Kalra PR, Anagnostopoulos C, Bolger AP, Coats AJS and Anker SD. The regulation and measurement of plasma volume in heart failure. Journal of the American College of Cardiology. 2002;39:1901-1908.

42. Zannad F and Rossignol P. Cardiorenal Syndrome Revisited. Circulation. 2018;138:929-44.

43. Rossignol P, Menard J, Fay R, Gustafsson F, Pitt B and Zannad F. Eplerenone survival benefits in heart failure patients post-myocardial infarction are independent from its diuretic and potassium-sparing effects.

Insights from an EPHESUS (Eplerenone Post-Acute Myocardial Infarction Heart Failure Efficacy and Survival Study) substudy. J Am Coll Cardiol. 2011;58:1958-66. 
Table 1. Baseline Characteristics according to Quartiles of Duarte-Derived Estimated Plasma Volume Status

Values are expressed as mean $\pm \mathrm{SD}, \mathrm{n}(\%)$ or median (25th to 75 th percentile)

ePVS, estimated plasma volume status; HF, heart failure; NYHA, New York Heart Association; BP, blood pressure; LVEF, left ventricular ejection fraction; ACEi, angiotensin converting enzyme inhibitor; ARB, angiotensin receptor blocker; eGFR, estimated glomerular filtration rate; BNP, brain natriuretic peptide; NT-proBNP, N-terminal-pro brain natriuretic peptide; LVM, left ventricular mass; LAV, left atrial volume; GLS, global longitudinal strain; KCCQ, Kansas City Cardiomyopathy Questionnaire.

* p-value adjusted for age and sex at entry.

**Natriuretic peptide z-score was calculated using both BNP and NT-proBNP.

Table 2. Multivariable Model of the Association between Clinical Profiles and Estimated Plasma Volume Status (per 1ml/g)

CI, confidence interval; HF, heart failure; NYHA, New York Heart Association; eGFR, estimated glomerular filtration rate; KCCQ, Kansas City Cardiomyopathy Questionnaire.

Table 3. Cox Proportional Hazard Model of Duarte-Derived Estimated Plasma Volume Status for the Primary Outcome

Model 1, univariable model.

Model 2, adjusted for age, female gender, body mass index, previous myocardial infarction, left ventricular ejection fraction, New York Heart Association III or IV, potassium and estimated glomerular filtration rate at baseline.

Model 3, adjusted for covariables in Model 2 plus natriuretic peptide (BNP or NT-proBNP) transformed by z-score.

HR, hazard ratio; CI, confidence interval; ePVS, estimated plasma volume status; eGFR, estimated glomerular filtration rate. 
Table 1. Baseline Characteristics according to Quartiles of Duarte-Derived Estimated Plasma Volume Status

\begin{tabular}{|c|c|c|c|c|c|c|}
\hline & \multicolumn{4}{|c|}{ ePVS quartiles } & \multirow[b]{2}{*}{ p-value } & \multirow[b]{2}{*}{$\begin{array}{c}\text { Adjusted } \\
\text { p-value* }\end{array}$} \\
\hline & $\begin{array}{l}\text { Quartile 1, } \\
<4.15 \\
(\mathrm{~N}=438)\end{array}$ & $\begin{array}{c}\text { Quartile 2, } \\
4.15-4.79 \\
(\mathrm{~N}=437)\end{array}$ & $\begin{array}{c}\text { Quartile 3, } \\
4.79-5.50 \\
(N=437)\end{array}$ & $\begin{array}{c}\text { Quartile 4, } \\
>5.50 \\
(\mathrm{~N}=435)\end{array}$ & & \\
\hline Age, yrs & $70.2 \pm 9.5$ & $71.9 \pm 9.7$ & $72.3 \pm 9.5$ & $72.0 \pm 9.8$ & 0.005 & - \\
\hline Female gender, $\mathbf{N}(\%)$ & $145(33.1 \%)$ & $219(50.1 \%)$ & $238(54.5 \%)$ & $270(62.1 \%)$ & $<0.0001$ & - \\
\hline Body mass index, $\mathrm{kg} / \mathrm{m}^{2}$ & $33.8 \pm 7.5$ & $33.1 \pm 7.4$ & $33.9 \pm 8.8$ & $34.2 \pm 8.6$ & 0.24 & 0.14 \\
\hline Obesity, N (\%) & $283(65.1 \%)$ & $278(63.8 \%)$ & $276(63.2 \%)$ & $284(65.7 \%)$ & 0.85 & 0.87 \\
\hline \multicolumn{7}{|l|}{ Medical history, N (\%) } \\
\hline Hypertension & $389(88.8 \%)$ & $391(89.5 \%)$ & $393(90.1 \%)$ & $399(91.7 \%)$ & 0.52 & 0.64 \\
\hline Diabetes & $142(32.4 \%)$ & $181(41.4 \%)$ & $208(47.7 \%)$ & $248(57.0 \%)$ & $<0.0001$ & $<0.0001$ \\
\hline Atrial fibrillation & $206(47.0 \%)$ & $185(42.3 \%)$ & $190(43.6 \%)$ & $156(35.9 \%)$ & 0.008 & 0.004 \\
\hline Myocardial infarction & $89(20.3 \%)$ & $83(19.0 \%)$ & $86(19.7 \%)$ & $100(23.0 \%)$ & 0.49 & 0.10 \\
\hline Prior HF hospitalization & $234(53.4 \%)$ & $242(55.4 \%)$ & $268(61.5 \%)$ & $284(65.3 \%)$ & 0.001 & $<0.0001$ \\
\hline \multicolumn{7}{|l|}{ Clinical profile } \\
\hline NYHA III+IV, N (\%) & $128(29.3 \%)$ & $131(30.0 \%)$ & $150(34.3 \%)$ & $202(46.7 \%)$ & $<0.0001$ & $<0.0001$ \\
\hline Orthopnea, N (\%) & $110(25.5 \%)$ & $107(24.9 \%)$ & $149(34.3 \%)$ & $173(40.0 \%)$ & $<0.0001$ & $<0.0001$ \\
\hline Jugular venous distention, $\mathbf{N}(\%)$ & $63(15.3 \%)$ & $65(15.6 \%)$ & $77(18.8 \%)$ & $92(22.6 \%)$ & 0.02 & 0.03 \\
\hline Leg edema, N (\%) & $285(65.2 \%)$ & $316(72.3 \%)$ & $318(72.8 \%)$ & $329(75.6 \%)$ & 0.006 & 0.001 \\
\hline Systolic BP, mmHg & $126.4 \pm 15.0$ & $128.4 \pm 16.5$ & $126.6 \pm 15.8$ & $128.6 \pm 16.1$ & 0.08 & 0.18 \\
\hline Heart rate, bpm & $69.5 \pm 11.5$ & $69.2 \pm 11.0$ & $68.5 \pm 11.5$ & $68.7 \pm 12.2$ & 0.54 & 0.39 \\
\hline LVEF, \% & $58.1 \pm 7.6$ & $58.0 \pm 8.1$ & $57.9 \pm 7.5$ & $58.8 \pm 7.9$ & 0.36 & 0.24 \\
\hline \multicolumn{7}{|l|}{ Medications, N (\%) } \\
\hline ACEi/ARB & $349(79.7 \%)$ & $332(76.0 \%)$ & $335(76.7 \%)$ & $352(80.9 \%)$ & 0.23 & 0.27 \\
\hline Beta-blocker & $332(75.8 \%)$ & $327(74.8 \%)$ & $344(78.7 \%)$ & $360(82.8 \%)$ & 0.02 & 0.003 \\
\hline Calcium channel blocker & $139(31.7 \%)$ & $182(41.6 \%)$ & $163(37.3 \%)$ & $185(42.5 \%)$ & 0.004 & 0.009 \\
\hline Loop diuretics & $374(85.4 \%)$ & $380(87.0 \%)$ & $402(92.0 \%)$ & $391(89.9 \%)$ & 0.01 & 0.007 \\
\hline Spironolactone & $212(48.4 \%)$ & $234(53.5 \%)$ & $221(50.6 \%)$ & $210(48.3 \%)$ & 0.36 & 0.38 \\
\hline \multicolumn{7}{|l|}{ Laboratory findings } \\
\hline Hemoglobin, g/dl & $15.0 \pm 0.9$ & $13.4 \pm 0.4$ & $12.3 \pm 0.4$ & $10.8 \pm 0.8$ & $<0.0001$ & $<0.0001$ \\
\hline Sodium, mmol/l & $139.8 \pm 3.0$ & $139.9 \pm 3.0$ & $139.5 \pm 3.1$ & $139.5 \pm 3.4$ & 0.22 & 0.09 \\
\hline Potassium, mmol/l & $4.2 \pm 0.4$ & $4.2 \pm 0.4$ & $4.2 \pm 0.4$ & $4.2 \pm 0.4$ & 0.61 & 0.63 \\
\hline Blood urea nitrogen, $\mathrm{mg} / \mathrm{dl}$ & $17.0 \pm 13.6$ & $19.3 \pm 13.5$ & $23.0 \pm 15.0$ & $25.6 \pm 15.9$ & $<0.0001$ & $<0.0001$ \\
\hline eGFR, $\mathrm{ml} / \mathrm{min} / 1.73 \mathrm{~m}^{2}$ & $69.4 \pm 21.1$ & $67.1 \pm 22.4$ & $61.7 \pm 20.3$ & $59.3 \pm 20.7$ & $<0.0001$ & $<0.0001$ \\
\hline Natriuretic peptide $\mathrm{z}$-score* $(\mathrm{N}=1,046)$ & $-0.2 \pm 1.0$ & $-0.0 \pm 0.9$ & $0.0 \pm 1.0$ & $0.2 \pm 1.1$ & 0.003 & 0.001 \\
\hline $\mathrm{BNP}, \mathrm{pg} / \mathrm{ml}(\mathrm{N}=690)$ & $\begin{array}{c}242 \\
(140-410)\end{array}$ & $\begin{array}{c}258 \\
(154-423)\end{array}$ & $\begin{array}{c}246 \\
(154-441)\end{array}$ & $\begin{array}{c}305 \\
(163-566)\end{array}$ & 0.09 & 0.041 \\
\hline NT-proBNP, pg/ml (N=356) & $\begin{array}{c}903 \\
(500-1404)\end{array}$ & $\begin{array}{c}882 \\
(528-1665)\end{array}$ & $\begin{array}{c}918 \\
(604-2424)\end{array}$ & $\begin{array}{c}1451 \\
(631-2582)\end{array}$ & 0.01 & 0.08 \\
\hline \multicolumn{7}{|l|}{ Echocardiography } \\
\hline LVM index, $\mathrm{g} / \mathrm{m}^{2}(\mathrm{~N}=635)$ & $110.0 \pm 30.1$ & $108.9 \pm 33.5$ & $109.2 \pm 30.4$ & $112.6 \pm 30.9$ & 0.69 & 0.20 \\
\hline LAV index, $\mathrm{mm}^{3} / \mathrm{m}^{2}(\mathrm{~N}=575)$ & $30.4 \pm 10.5$ & $32.5 \pm 16.0$ & $31.0 \pm 13.7$ & $30.9 \pm 13.5$ & 0.61 & 0.76 \\
\hline $\mathrm{E} / \mathrm{A}$ ratio $(\mathrm{N}=397)$ & $1.3 \pm 0.8$ & $1.4 \pm 0.7$ & $1.4 \pm 0.7$ & $1.4 \pm 0.7$ & 0.85 & 0.75 \\
\hline E/e' ratio $(N=275)$ & $11.7 \pm 5.4$ & $15.2 \pm 6.9$ & $14.1 \pm 5.8$ & $16.0 \pm 5.5$ & 0.0005 & 0.0007 \\
\hline GLS $(\mathbf{N}=333)$ & $-15.1 \pm 3.2$ & $-15.1 \pm 3.8$ & $-15.2 \pm 3.4$ & $-16.4 \pm 3.3$ & 0.047 & 0.09 \\
\hline KCCQ overall score & $62.1 \pm 23.4$ & $59.9 \pm 23.1$ & $57.8 \pm 22.5$ & $52.8 \pm 23.7$ & $<0.0001$ & $<0.0001$ \\
\hline
\end{tabular}


Table 2. Multivariable Model of the Association between Clinical Profiles and Estimated Plasma Volume Status (per $1 \mathrm{ml} / \mathrm{g}$ )

\begin{tabular}{lccc}
\hline & Beta & $\mathbf{9 5 \%}$ CI & $\begin{array}{c}\mathbf{R}^{2}=\mathbf{0 . 1 6} \\
\text { p-value }\end{array}$ \\
\hline (Constant) & 4.41 & $3.76-5.05$ & $<0.001$ \\
Age, yrs (per 5 yrs) & 0.04 & $0.01-0.07$ & 0.006 \\
Female gender & 0.42 & $0.32-0.52$ & $<0.001$ \\
Body mass index & -0.01 & $-0.02--0.003$ & 0.004 \\
Diabetes & 0.32 & $0.22-0.43$ & $<0.001$ \\
Atrial fibrillation & -0.13 & $-0.23--0.03$ & 0.009 \\
Prior HF hospitalization & 0.25 & $0.15-0.35$ & $<0.001$ \\
Coronary artery revascularization & 0.15 & $0.04-0.25$ & 0.008 \\
NYHA III or IV & 0.13 & $0.02-0.24$ & 0.018 \\
Orthopnea & 0.13 & $0.02-0.24$ & 0.019 \\
Jugular venous distention & 0.17 & $0.04-0.30$ & 0.011 \\
Leg edema & 0.16 & $0.06-0.27$ & 0.003 \\
Use of Beta-blocker & 0.17 & $0.05-0.29$ & 0.005 \\
eGFR, ml/min/1.73m ${ }^{2}$ (per 5mI/min/1.73m $\left.{ }^{2}\right)$ & -0.03 & $-0.04--0.02$ & $<0.001$ \\
KCCQ overall summary score $(\mathbf{p e r} \mathbf{5})$ & -0.02 & $-0.03--0.01$ & $<0.001$ \\
\hline
\end{tabular}


Table 3. Cox Proportional Hazard Model of Duarte-Derived Estimated Plasma Volume Status for the Primary Outcome

\begin{tabular}{|c|c|c|c|c|c|c|c|c|c|}
\hline \multirow[t]{2}{*}{ Primary endpoint } & \multicolumn{3}{|c|}{ Model 1} & \multicolumn{3}{|c|}{ Model 2} & \multicolumn{3}{|c|}{ Model 3} \\
\hline & HR & $95 \% \mathrm{CI}$ & p-value & HR & $95 \% \mathrm{CI}$ & p-value & HR & $95 \% \mathrm{CI}$ & p-value \\
\hline ePVS Continuous (per 1ml/g) & 1.33 & $1.24-1.44$ & $<0.001$ & 1.27 & $1.18-1.37$ & $<0.001$ & 1.23 & $1.10-1.37$ & $<0.001$ \\
\hline \multicolumn{10}{|l|}{ ePVS Categorical } \\
\hline Q1 & & (reference) & & & (reference) & & & (reference) & \\
\hline Q2 & 1.02 & $0.78-1.35$ & 0.87 & 1.07 & $0.81-1.41$ & 0.63 & 1.15 & $0.80-1.65$ & 0.44 \\
\hline Q3 & 1.40 & $1.08-1.82$ & 0.01 & 1.39 & $1.07-1.80$ & 0.01 & 1.25 & $0.88-1.78$ & 0.22 \\
\hline Q4 & 2.16 & $1.69-2.75$ & $<0.001$ & 2.00 & $1.55-2.59$ & $<0.001$ & 1.79 & $1.28-2.50$ & $<0.001$ \\
\hline \multicolumn{10}{|l|}{ ePVS and eGFR interplay } \\
\hline ePVS $<5.5 \mathrm{ml} / \mathrm{g} \&$ eGFR $>60 \mathrm{ml} / \mathrm{min} / 1.73 \mathrm{~m}^{2}$ & & (reference) & & & (reference) & & & (reference) & \\
\hline ePVS $<5.5 \mathrm{ml} / \mathrm{g} \& \mathrm{eGFR}<60 \mathrm{ml} / \mathrm{min} / 1.73 \mathrm{~m}^{2}$ & 1.53 & $1.23-1.89$ & $<0.001$ & 1.28 & $0.94-1.75$ & 0.12 & 1.99 & $1.31-3.00$ & 0.001 \\
\hline ePVS $>5.5 \mathrm{ml} / \mathrm{g} \& \mathrm{eGFR}>60 \mathrm{ml} / \mathrm{min} / 1.73 \mathrm{~m}^{2}$ & 1.90 & $1.41-2.55$ & $<0.001$ & 1.83 & $1.35-2.47$ & $<0.001$ & 2.00 & $1.36-2.92$ & $<0.001$ \\
\hline $\begin{array}{c}\text { ePVS }>5.5 \mathrm{ml} / \mathrm{g} \& \mathrm{eGFR}<60 \mathrm{ml} / \mathrm{min} / 1.73 \mathrm{~m}^{2} \\
\text { p-value for interaction } \\
\text { with eGFR }\end{array}$ & 2.65 & $2.08-3.37$ & $<0.001$ & 2.13 & $1.51-3.00$ & $<0.001$ & 2.59 & $1.63-4.11$ & $<0.001$ \\
\hline Continuous & & & 0.45 & & & & & & \\
\hline Categorical & & & 0.65 & & & & & & \\
\hline
\end{tabular}




\section{Graphic abstract}

\section{STUDY DESIGN}

1,747 patients with HFpEF in the TOPCAT Americas

Duarte-derived ePVS

ePVS $(\mathrm{mL} / \mathrm{g})=(1-\mathrm{Hct}) / \mathrm{Hb} \times 100$

Hakim-derived ePVS

Actual PV $(\mathrm{mL})=(1-\mathrm{Hct}) \times(\mathrm{a}+\mathrm{b} \times$ body weight $)$

Ideal PV $(\mathrm{mL})=\mathrm{c} \times$ body weight

ePVS (\%) $=[($ actual PV - ideal PV)/ideal PV $] \times 100$

(male; $a=1530, b=41.0, c=39$ : female; $a=864, b=47.9, c=40$ )

\section{OBJECTIVE}

1) To study associations of Duarte-derived ePVS with clinical characteristics and outcomes

2) To compare the discriminative prognostic values of Duartederived ePVS and Hakim-derived ePVS on top of the clinical model

\section{RESULTS}

Prediction of cardiovascular outcomes in patients with HFpEF with plasma volume estimation

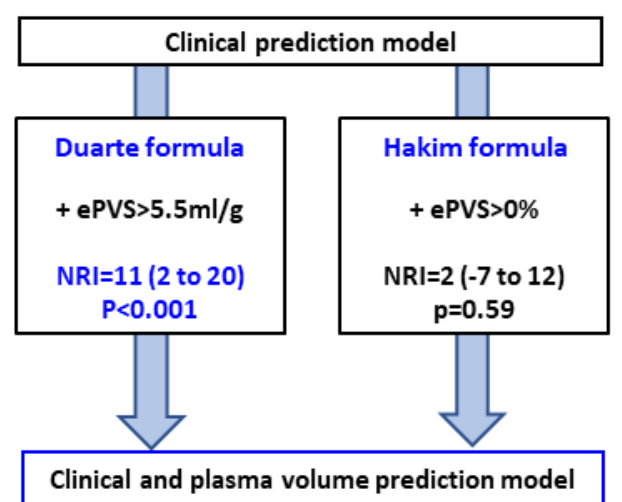




\section{Figure 1. Kaplan-Meier Survival Curves for the Primary Outcome according to Estimated Plasma Volume Status}

Higher ePVS increases the risk of major cardiovascular events, and the combination of ePVS and eGFR was associated with a higher risk of cardiovascular events.

Estimated plasma volume status (ePVS): Quartile 1, <4.15 ml/g; Quartile 2, 4.15-4.79 ml/g; Quartile 3, 4.79-5.50 ml/g; Quartile 4, >5.50 ml/g.

ePVS, estimated plasma volume status; eGFR, estimated glomerular filtration rate.

Figure 2. Comparison of the Discriminative Values of Plasma Volume Estimated from the Duarte and Hakim Formulas for the Primary Outcome

PV estimated from Duarte formula improved prognostic performance on top of clinical and routine variables (including renal function and natriuretic peptides), whereas PV estimated from Hakim formula did not.

BMI, body mass index; MI, myocardial infarction; LVEF, left ventricular ejection fraction; NYHA, New York Heart Association; eGFR, estimated glomerular filtration rate; BNP, B-type natriuretic peptide; NT proBNP, N-terminal pro-Btype natriuretic peptide; ePVS, estimated plasma volume status; NRI, net reclassification improvement. 
Figure 1. Kaplan-Meier Survival Curves for the Primary Outcome according to Estimated Plasma Volume Status

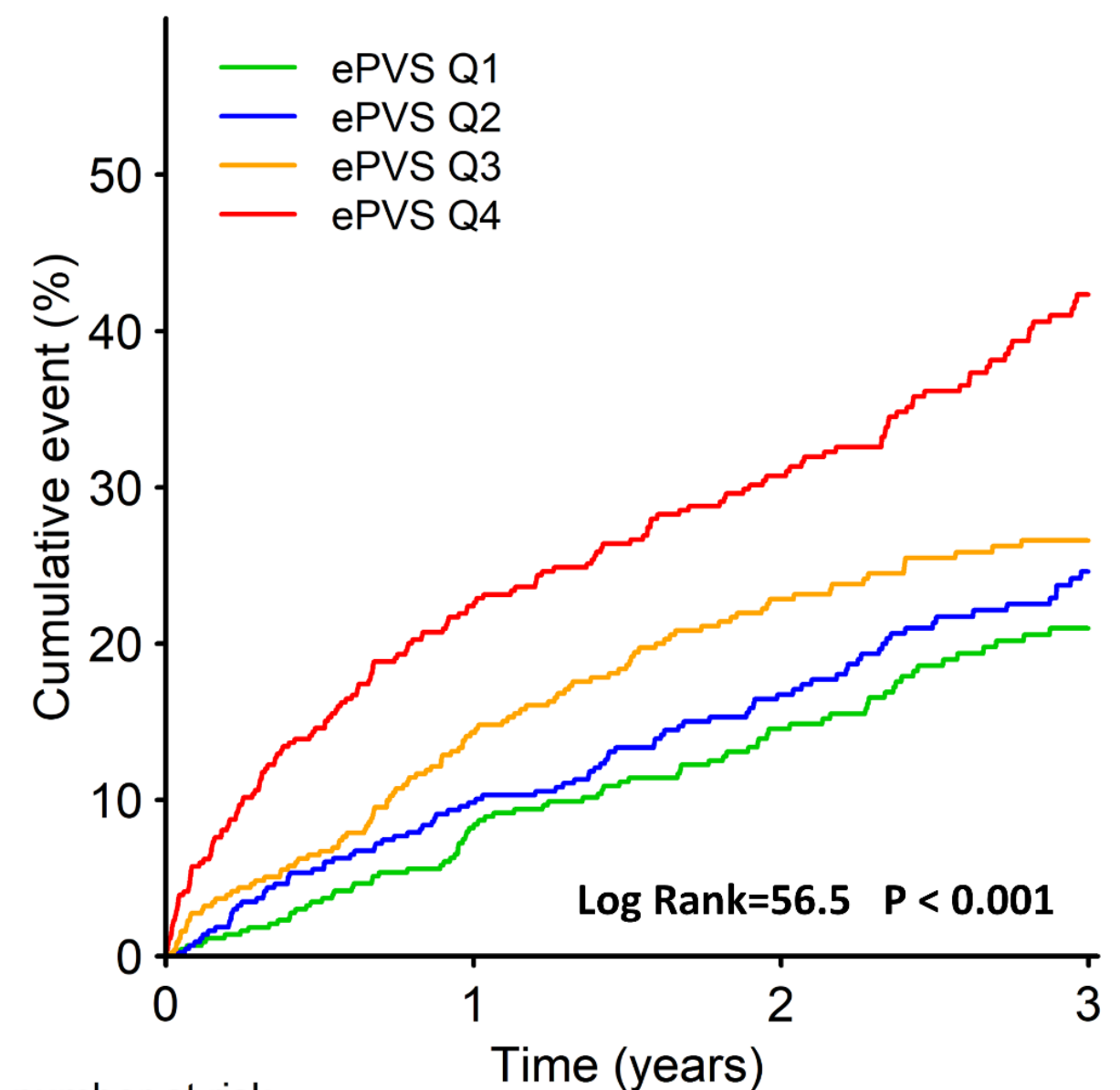

number at risk

$\begin{array}{lll}- & 438 & 382 \\ - & 437 & 371 \\ - & 437 & 351 \\ - & 435 & 319\end{array}$

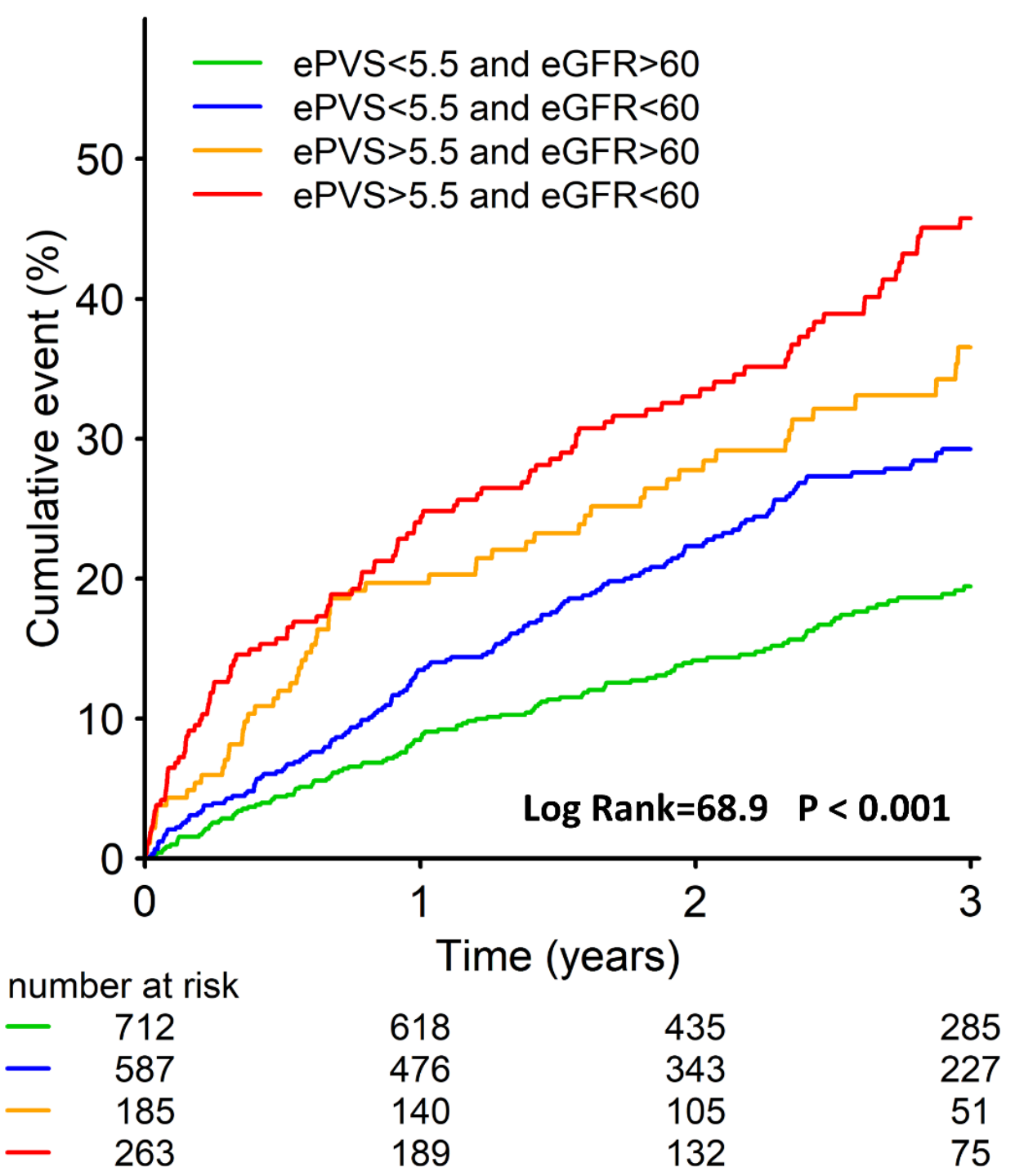


Figure 2. Comparison of the Discriminative Values of Plasma Volume Estimated from the Duarte and Hakim Formulas for the Primary Outcome

age, sex, BMI, prior MI, LVEF, NYHA III or IV, potassium, eGFR and natriuretic peptide (BNP or NT-proBNP)

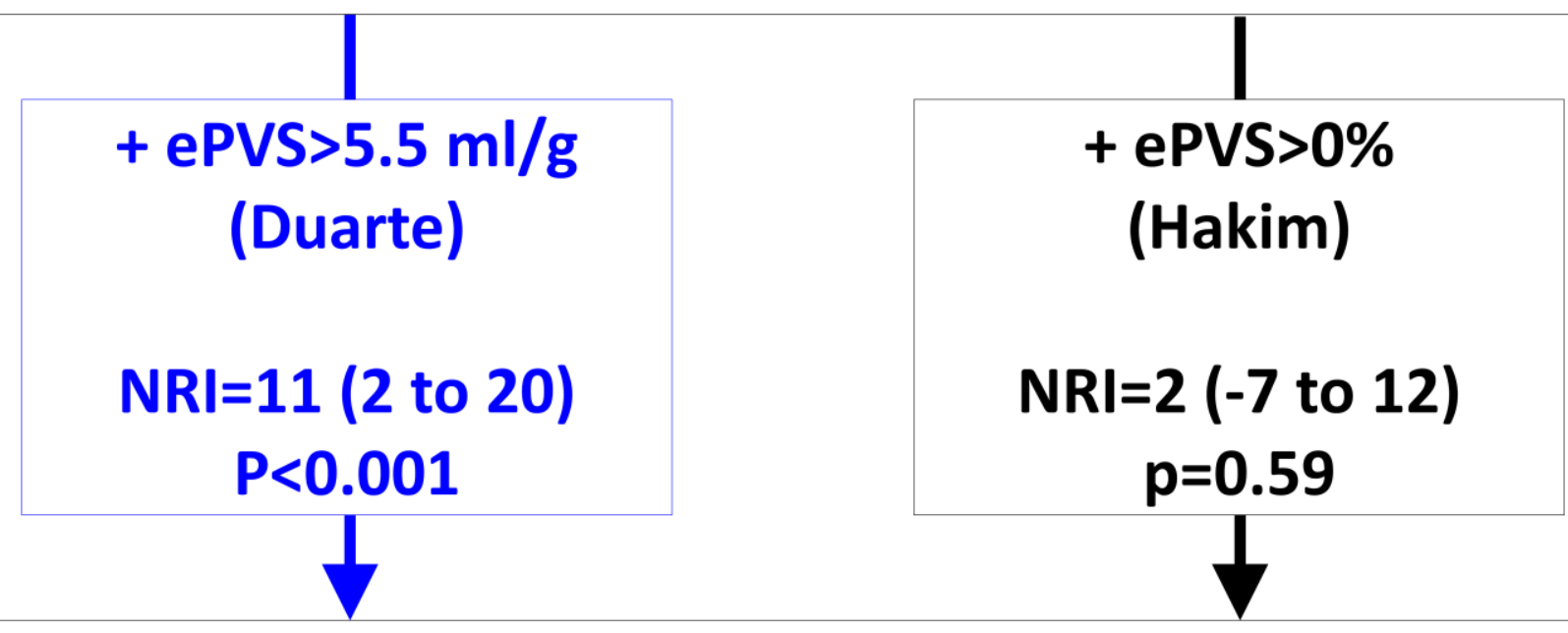

age, sex, BMI, prior MI, LVEF, NYHA III or IV, potassium, eGFR and natriuretic peptide (BNP or NT-proBNP)
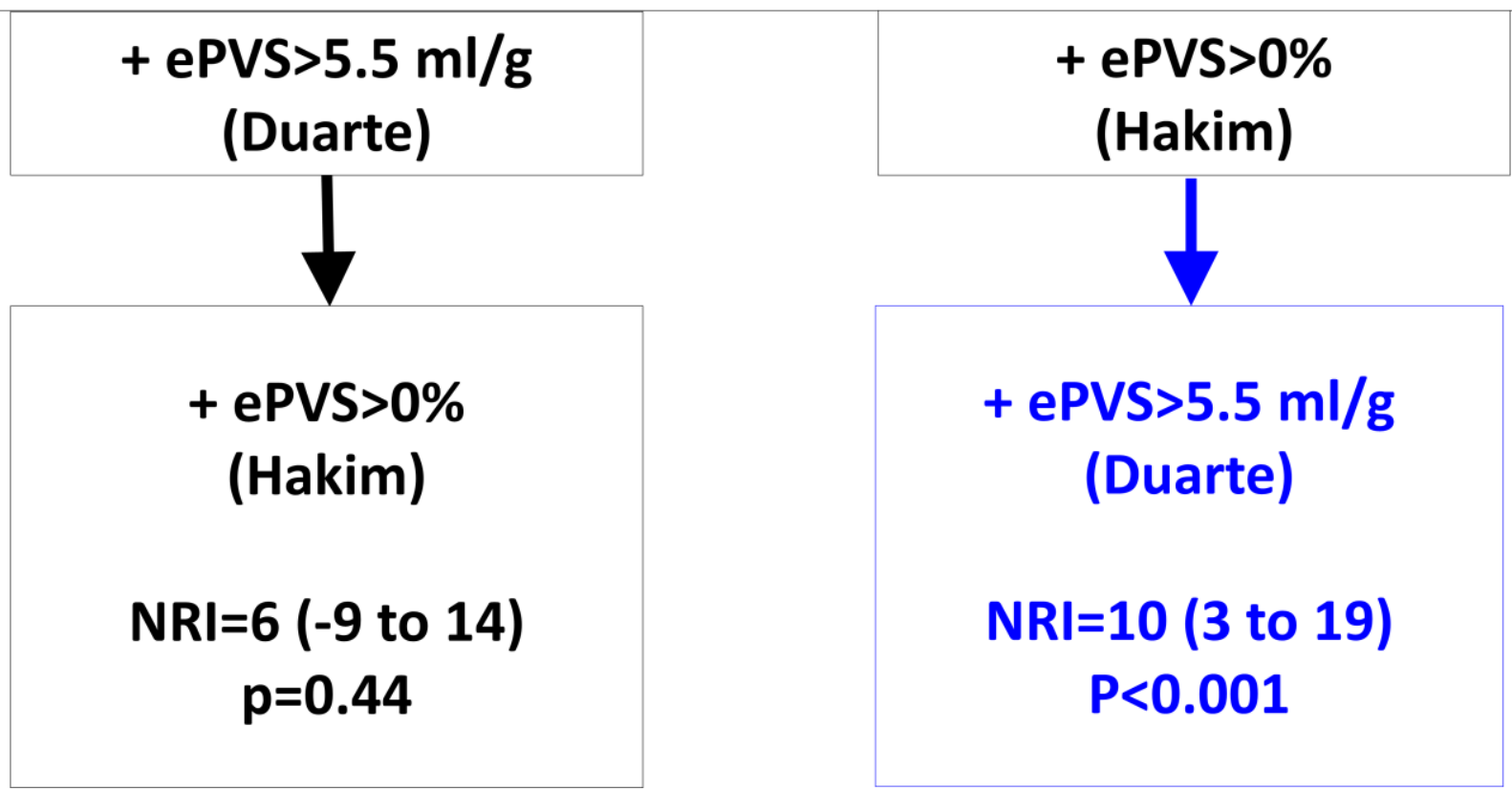
Supplementary table 1. Candidate Clinical Variables Predicting Duarte-Derived Estimated Plasma Volume Status

\begin{tabular}{|c|c|c|c|c|c|}
\hline Variables & $\begin{array}{c}\% \text { missing } \\
\text { value }\end{array}$ & Variables & $\begin{array}{c}\% \text { missing } \\
\text { value }\end{array}$ & Variables & $\begin{array}{c}\% \text { missing } \\
\text { value }\end{array}$ \\
\hline Age & 0 & Clinical profiles & & Laboratory findings & \\
\hline Female & 0 & NYHA III or IV & 0.2 & White blood cell & 0.2 \\
\hline Body mass index & 0.4 & Orthopnea & 1.1 & Alkaline phosphatase & 1.1 \\
\hline Medical history & & Jugular venous distention & 5.9 & Albumin & 5.9 \\
\hline Hypertension & 0.1 & Leg edema & 0.1 & Sodium & 0.1 \\
\hline Diabetes & 0.1 & Systolic BP & 0.1 & Potassium & 0.1 \\
\hline Dyslipidemia & 0.1 & Heart rate & 0.2 & eGFR & 0.2 \\
\hline Use of Insulin & 0.1 & Left ventricular ejection fraction & 0 & KCCQ overall score & 0 \\
\hline Atrial fibrillation & 0.1 & Medications & 0 & & \\
\hline Previous myocardial infarction & 0.1 & ACEi or ARB & 0 & & \\
\hline Coronary artery revascularization & 0.1 & Beta-blocker & 0 & & \\
\hline Prior HF admission & 0.1 & Calcium channel blocker & 0 & & \\
\hline Stroke & 0.1 & Loop diuretics & 0 & & \\
\hline Peripheral artery disease & 0.1 & Spironolactone & 0 & & \\
\hline Chronic obstructive pulmonary disease & 0.1 & & & & \\
\hline
\end{tabular}

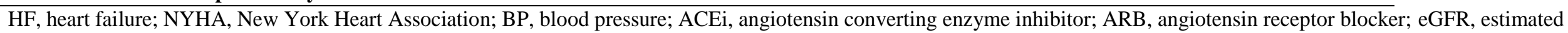
glomerular filtration rate; KCCQ, Kansas City Cardiomyopathy Questionnaire. 
Supplementary table 2. Multivariable Model for the Association between Clinical Profiles and the Highest Quartile of Estimated Plasma Volume Status ( $>5.5 \mathrm{ml} / \mathrm{g}$ )

\begin{tabular}{lccc}
\hline & OR & 95\% CI & p-value \\
\hline Age $>$ 75yrs & 1.33 & $1.04-1.70$ & 0.02 \\
Female & 1.85 & $1.46-2.35$ & $<0.001$ \\
Diabetes & 1.88 & $1.47-2.41$ & $<0.001$ \\
Prior HF hospitalization & 1.23 & $0.96-1.58$ & 0.10 \\
NYHA III or IV & 1.65 & $1.30-2.10$ & $<0.001$ \\
Systolic BP> 110mmHg & 0.69 & $0.46-0.99$ & 0.05 \\
Albumin $>\mathbf{3 . 7 m g / d l}$ & 2.27 & $1.78-2.90$ & $<0.001$ \\
eGFR $>\mathbf{6 0 m l} / \mathbf{m i n} / \mathbf{1 . 7 3 m} \mathbf{m}^{2}$ & 0.68 & $0.53-0.86$ & 0.001 \\
\hline
\end{tabular}

OR, odd ratio; CI, confidence interval; HF, heart failure; NYHA, New York Heart Association; BP, blood pressure; eGFR, estimated glomerular filtration rate. 


\section{Supplementary table 3. Cox Proportional Hazards Models of the association between Estimated Plasma Volume Status and Clinical Outcomes}

\begin{tabular}{|c|c|c|c|c|c|c|c|c|c|}
\hline \multirow[t]{2}{*}{ All-cause mortality } & \multicolumn{3}{|c|}{ Model 1} & \multicolumn{3}{|c|}{ Model 2} & \multicolumn{3}{|c|}{ Model 3} \\
\hline & HR & $95 \% \mathrm{CI}$ & p-value & Categorical & $95 \% \mathrm{CI}$ & p-value & HR & $95 \% \mathrm{CI}$ & p-value \\
\hline ePVS Continuous (per $1 \mathrm{ml} / \mathrm{g}$ ) & 1.25 & $1.14-1.37$ & $<0.001$ & 1.21 & $1.10-1.32$ & $<0.001$ & 1.07 & $0.94-1.22$ & 0.29 \\
\hline \multicolumn{10}{|l|}{ ePVS Categorical } \\
\hline Q1 & & (reference) & & & (reference) & & & (reference) & \\
\hline Q2 & 0.92 & $0.68-1.27$ & 0.62 & 0.94 & $0.68-1.29$ & 0.69 & 0.81 & $0.54-1.23$ & 0.33 \\
\hline Q3 & 1.45 & $1.09-1.93$ & 0.011 & 1.41 & $1.05-1.89$ & 0.02 & 1.06 & $0.72-1.57$ & 0.76 \\
\hline Q4 & 1.60 & $1.20-2.12$ & 0.001 & 1.52 & $1.13-2.05$ & 0.005 & 1.04 & $0.71-1.54$ & 0.83 \\
\hline \multicolumn{10}{|l|}{ ePVS and eGFR interplay } \\
\hline ePVS $<5.5 \&$ eGFR $>60$ & & (reference) & & & (reference) & & & (reference) & \\
\hline $\mathrm{ePVS}<5.5 \& \mathrm{eGFR}<60$ & 1.86 & $1.45-2.38$ & $<0.001$ & 1.46 & $1.02-2.10$ & 0.04 & 2.12 & $1.28-3.49$ & 0.003 \\
\hline ePVS $>5.5 \&$ eGFR $>60$ & 1.57 & $1.09-2.26$ & 0.02 & 1.59 & $1.10-2.31$ & 0.01 & 1.61 & $0.99-2.60$ & 0.051 \\
\hline ePVS $>5.5 \&$ eGFR $<60$ & 2.29 & $1.71-3.07$ & $<0.001$ & 1.82 & $1.21-2.74$ & 0.004 & 2.00 & $1.13-3.51$ & 0.02 \\
\hline \multicolumn{10}{|c|}{ p-value for interaction with eGFR } \\
\hline Continuous & & & 0.52 & & & & & & \\
\hline Categorical & & & 0.30 & & & & & & \\
\hline \multirow[t]{2}{*}{ CV mortality } & \multicolumn{3}{|c|}{ Model 1} & \multicolumn{3}{|c|}{ Model 2} & \multicolumn{3}{|c|}{ Model 3} \\
\hline & HR & $95 \% \mathrm{CI}$ & p-value & HR & $95 \% \mathrm{CI}$ & p-value & HR & $95 \% \mathrm{CI}$ & p-value \\
\hline ePVS Continuous (per 1ml/g) & 1.22 & $1.08-1.38$ & 0.001 & 1.18 & $1.04-1.33$ & 0.01 & 1.09 & $0.92-1.29$ & 0.34 \\
\hline \multicolumn{10}{|l|}{ ePVS Categorical } \\
\hline Q1 & & (reference) & & & (reference) & & & (reference) & \\
\hline Q2 & 0.93 & $0.62-1.40$ & 0.74 & 0.93 & $0.62-1.40$ & 0.72 & 0.66 & $0.38-1.16$ & 0.14 \\
\hline Q3 & 1.36 & $0.94-1.99$ & 0.11 & 1.29 & $0.88-1.90$ & 0.19 & 0.86 & $0.51-1.46$ & 0.57 \\
\hline Q4 & 1.53 & $1.05-2.21$ & 0.03 & 1.39 & $0.95-2.06$ & 0.09 & 1.004 & $0.61-1.66$ & 0.99 \\
\hline \multicolumn{10}{|l|}{ ePVS and eGFR interplay } \\
\hline ePVS $<5.5 \&$ eGFR $>60$ & & (reference) & & & (reference) & & & (reference) & \\
\hline ePVS $<5.5 \&$ eGFR<60 & 1.95 & $1.41-2.69$ & $<0.001$ & 1.61 & $0.99-2.59$ & 0.052 & 2.90 & $1.49-5.65$ & 0.002 \\
\hline ePVS>5.5 \& eGFR>60 & 1.52 & $0.93-2.48$ & 0.09 & 1.51 & $0.91-2.49$ & 0.11 & 2.02 & $1.06-3.84$ & 0.03 \\
\hline ePVS $>5.5 \&$ eGFR $<60$ & 2.22 & $1.50-3.29$ & $<0.001$ & 1.82 & $1.05-3.14$ & 0.03 & 2.61 & $1.22-5.55$ & 0.01 \\
\hline \multicolumn{10}{|c|}{ p-value for interaction with eGFR } \\
\hline Continuous & & & 0.59 & & & & & & \\
\hline Categorical & & & 0.36 & & & & & & \\
\hline \multirow[t]{2}{*}{ HF hospitalization* } & \multicolumn{3}{|c|}{ Model 1} & \multicolumn{3}{|c|}{ Model 2} & \multicolumn{3}{|c|}{ Model 3} \\
\hline & HR & $95 \% \mathrm{CI}$ & p-value & HR & $95 \% \mathrm{CI}$ & p-value & HR & $95 \% \mathrm{CI}$ & p-value \\
\hline ePVS Continuous (per 1ml/g) & 1.40 & $1.30-1.52$ & $<0.001$ & 1.33 & $1.22-1.45$ & $<0.001$ & 1.32 & $1.18-1.49$ & $<0.001$ \\
\hline \multicolumn{10}{|l|}{ ePVS Categorical } \\
\hline Q1 & & (reference) & & & (reference) & & & (reference) & \\
\hline Q2 & 1.15 & $0.83-1.59$ & 0.39 & 1.21 & $0.88-1.68$ & 0.25 & 1.44 & $0.94-2.20$ & 0.10 \\
\hline Q3 & 1.45 & $1.07-1.97$ & 0.02 & 1.41 & $1.03-1.93$ & $\mathbf{0 . 0 3}$ & 1.42 & $0.93-2.18$ & 0.11 \\
\hline Q4 & 2.58 & $1.95-3.43$ & $<0.001$ & 2.36 & $1.75-3.17$ & $<0.001$ & 2.34 & $1.57-3.47$ & $<0.001$ \\
\hline \multicolumn{10}{|l|}{ ePVS and eGFR interplay } \\
\hline ePVS $<5.5 \&$ eGFR $>60$ & & (reference) & & & (reference) & & & (reference) & \\
\hline ePVS $<5.5 \&$ eGFR $<60$ & 1.35 & $1.05-1.74$ & 0.02 & 1.14 & $0.79-1.64$ & 0.48 & 1.43 & $0.89-2.30$ & 0.14 \\
\hline ePVS $>5.5 \&$ eGFR $>60$ & 1.99 & $1.43-2.77$ & $<0.001$ & 1.85 & $1.32-2.58$ & $<0.001$ & 1.78 & $1.16-2.72$ & 0.01 \\
\hline ePVS $>5.5 \&$ eGFR $<60$ & 2.89 & $2.21-3.78$ & $<0.001$ & 2.30 & $1.56-3.39$ & $<0.001$ & 2.57 & $1.54-4.28$ & $<0.001$ \\
\hline p-value for interaction wit & & & & & & & & & \\
\hline Continuous & & & 0.25 & & & & & & \\
\hline Categorical & & & 0.73 & & & & & & \\
\hline
\end{tabular}

Model 2, adjusted for age, female, body mass index, previous myocardial infarction, left ventricular ejection fraction, New York Heart Association of III or IV, potassium and estimated glomerular filtration rate at baseline.

Model 3, adjusted for covariables in Model 2 plus natriuretic peptide (BNP or NT-proBNP) transformed by z-score.

*Time-to-event analysis was performed using the Fine-Gray competing risk model with HF hospitalization as outcome event and all-cause mortality as competing risk.

HR, hazard ratio; CI, confidence interval; ePVS, estimated plasma volume status; eGFR, estimated glomerular filtration rate; $\mathrm{CV}$, cardiovascular. 
Supplementary table 4. Comparison of Discriminative Values of Estimated Plasma Volume Status according the Duarte and Hakim formulas on the Top of Clinical Covariates for the Primary Outcome

\begin{tabular}{|c|c|c|c|c|c|}
\hline & & NRI $(95 \%$ CI $)$ & p-value & IDI (95\% CI) & p-value \\
\hline $\mathrm{ePVS} \geq 5.5 \mathrm{ml} / \mathrm{g}$ & on the top of clinical variables* & $11.0(2.0-19.6)$ & $<0.001$ & $0.70(0.01-2.20)$ & 0.04 \\
\hline by Duarte formula & on the top of clinical variables* + ePVS $>0 \%$ by Hakim & $10.3(2.9-18.5)$ & $<0.001$ & $0.80(0.01-2.10)$ & 0.04 \\
\hline ePVS $>0 \%$ & on the top of clinical variables* & $2.1(-7.4-11.7)$ & 0.59 & $-0.01(-0.11-0.56)$ & 0.99 \\
\hline by Hakim formula & on the top of clinical variables* $+\mathrm{ePVS} \geq 5.5 \mathrm{ml} / \mathrm{g}$ by Duarte & $5.8(-8.5-14.03)$ & 0.44 & $0.10(-0.05-1.15)$ & 0.24 \\
\hline
\end{tabular}

myocardial infarction, left ventricular ejection fraction, New York Heart Association class of III or IV, potassium, estimated glomerular filtration rate and natriuretic peptide (z-score) at baseline.

NRI, net reclassification improvement; IDI, integrated discrimination index; CI, confidence interval; ePVS, estimated plasma volume status. 